\title{
News from the International Federation of Robotics for Robotica
}

\section{9th ISR to be held in Birmingham}

The 29th International Symposium on Robotics is being held in Birmingham, UK from 27 to 30 April 1998. It will be hosted by the British Robot Association (BRA) and fully supported by the International Federation of Robotics (IFR) and the Institution of Electrical Engineers (IEE).

With a theme of Advanced Robotic Solutions Beyond 2000, the conference will be the ideal platform for the presentation of the latest research and development work across the full range of automation and robotic technologies from around the globe.

Even at this early stage, the organisers report that the initial Call for Papers has resulted already in abstract submissions from leading R\&D establishments across 25 countries.

In addition to the ISR, separate concurrent sessions will be running covering new application sectors for robotics in the following areas: food and agriculture, medical and healthcare, underwater, nuclear, space and defence, and service robots for construction, transport and domestic and leisure.

Submissions (up to 200 words) are currently being accepted with a closing date of 28 October 1997

The annual ISR event is widely accepted as the most highly-regarded robotics conference in the world, moving between Europe, Asia and the US. In an unprecedented move, the BRA has reached agreement with DMG Business Media Ltd to organise the 1998 event and to launch Automation \& Robotics 98, a major exhibition of industrial robots, automation equipment and ancillaries, alongside the conference at the National Exhibition Centre, Birmingham.

The major industrial robot suppliers are reportedly already showing considerable interest in this inaugural event with a number of key players already booked to exhibit. Industrial workshops will be held within the hall area of the exhibition to focus on successful implementation of automation and robot technologies.

Mike Wilson, president of the BRA, commented: 'This will be the most significant automation showcase to be held in the UK for many years. It provides an excellent opportunity for suppliers to demonstrate their products and services to the UK market.'

Commenting on the symposium, he added: 'The BRA is very proud to be hosting the 29th ISR in our 21st anniversary year. The ISR is acknowledged world-wide to be the leading event of its kind, an ideal opportunity to present new work to leading industrial and research communities and network with new and existing friends and contacts from other nations. The 29th ISR is a 'must attend' event for 1998 and I very much look forward to what will be a truly international event.'

Abstract submission for the conference, or general enquiries on the events should be directed to Dave Tellett, Automation \& Robotics/ISR 98, DMG Business Media Ltd, Queensway House, 2 Queensway, Redhill, Surrey RH1 1QS, UK.

\section{World Industial Robots 1997}

According to World Industrial Robots 1997, the investment in robots is set to grow by $13 \%$ a year between 1996 and 2000. This will take the yearly supply of robots of the six major users-Japan, the US, Germany, Italy, France and the UK - from 65,061 in 1996 to 103,331 units in 2000. In the same period, the total world shipment of robots is expected to grow from 80,529 in 1996 to 131,131 units in 2000. According to the report, world-wide sales of industrial robots peaked in 1990 with a total of almost 80,000 units. Following the recession of 1991 to 1993 , sales of robots plummeted to about 55,000 units in 1993. The world market showed a small increase in 1994 with sales of 56,500. A more solid recovery came in 1996 when global sales increased by $11 \%$, reaching almost 80,500 , or more or less the same level as the record year of 1990.

The main drop in sales between 1990 and 1993 was accounted for by the sharp drop in robot supply in Japan, from around 60,000 to under 30,000 in 1994. In 1995, the Japanese market began to recover to the extent that 36,500 new robots were delivered - a rise of $23 \%$ over 1994. By 1996 shipments had reached 39,000. In the US, after three years of yearly growth rates of $30 \%$, the market fell back by $5 \%$ in 1996 . But modest growth was recorded in Italy $(+3 \%)$. For the third year in a row, there was double digit growth in France, with 23\% recorded in 1996 over 1995. The UK experienced a roller-coaster ride from a growth of $84 \%$ in 1994 to $27 \%$ in 1995 and back to $41 \%$ in 1996 . The German market experienced incredible strength, increasing by over $40 \%$ per year in both 1995 and 1996. This more than compensated for the depressed years of 1991 through to 1993.

In the Far East, the Republic of Korea sustained an average yearly growth rate of $47 \%$ between 1991 and 1996 - albeit from a relatively low base. In 1996 it increased at 'only' $16 \%$ - roughly the same growth rate as that in Australia.

Less dramatic was the change of the market in Taiwan which for the third year in a row experienced a growth rate of $10 \%$. In Singapore, 800 new robots were installed between 1993 and 1994; in the following 